\title{
PSEUDOANEURYSM OF THE LEFT HEPATIC ARTERY - A COMPLICATION FOLLOWING LAPAROSCOPIC CHOLECYSTECTOMY - A CASE REPORT
}

\author{
Ignatov V., K. Ivanov, N. Kolev, A. Tonev \\ Department of General and Operative Surgery, St. Marina Varna University Hospital
}

\author{
Reviewed by: prof. R. Madjov
}

Key words: pseudoaneurism, left hepatic artery, laparoscopic cholecystectomy

Pseudoaneurysms of the hepatic artery are infrequent, but potentially fatal. The classical triad of upper gastrointestinal bleeding, pain in the right upper quadrant and obstructive jaundice described by Quincke is present in $32 \%$ of patients. Apart from the performance of percutaneous techniques, such lesions are fundamentally produced as a result of surgery. The causal surgical techniques may sometimes be quite complex, though in other cases they are common (e.g. laparoscopic cholecystectomy). Knowledge of such aneurysms is therefore of great interest for general surgeons, with a view to prompt diagnosis and adequate management of potential digestive bleeding. In such cases endoscopy and retrograde cholangiography may be performed before arteriography.

Of the 104 previously reported instances, most were discovered at necropsy following sudden death from rupture of the aneurysm (half into the peritoneal cavity, half into the gastro-intestinal tract). Two years ago, Sampsel, Barry and Steele (26) reported that a total of 90 instances of hepatic-artery aneurysm was available in the medical literature. Since then 14 additional cases have been described. These reports have been made by Dwight and Ratcliffe, McGregor (20), Siev (30), Wolfgang-Schega (27), Kruckemeyer (17), Berschadskij (3), Gamarski and Netto (8), Barnett and Wagner (2) Quattlebaum (24), Hess (13) and Giuseffi and Collins (10). In addition, aneurysmal arteriopathy has been noted along the celiac axis on some 35 occasions, 918 along the cystic artery on some five occasions, 6 along the gastric arteries on five occasions $(6,26,29)$ and but once in the superior pancreaticoduodenal artery (26). Although women are more vulnerable than men to disease of the gallbladder, they have had only one fourth of the hepatic aneurysms (19) The average age of patients is recorded as approximately 38 years (19). Prone as they are to rupture, these aneurysms often perforate into the peritoneal cavity, producing sudden shock and death, or

\footnotetext{
Address for correspondence:

Kr. Ivanov, Dept. of General and Operative Surgery, St. Marina University Hospital, Prof. P. Stoyanov Medical University of Varna; BG-9002 Varna, 1, Hristo Smirnenski Street, Bulgaria e-mail: teraton@abv.bg,kivanov@gisurgery.bg
}

they may perforate into the biliary-duct system resulting in hematemesis or melena, or both.

Occasionally, there is direct penetration into the duodenum or stomach. The classic triad of symptoms is understandable. This is pain, gastro-intestinal hemorrhage, and frequently jaundice. Jaundice can be produced by constrictive pressure on the biliarv ducts with or without actual perforation and bleeding. There have been only 21 instances $(7,10,24)$ in which the aneurysm has been recognized at the operating table during life. Thirteen of these patients died postoperatively. Only eight patients (and the diagnosis remains in doubt in three of these) $(1,4,13)$ have survived operation despite a variety of remedial attempts $(4,7,10,13,16,22,24)$. As far as we can ascertain from rather careful perusal of the available literature, excision of the aneurysm has not been reported previously.

\section{CASE REPORT}

We present a 63-year old woman with anamnesis gastrointestinal bleeding (melena), 2 months after laparoscopic cholecystectomy with hospital admission for a jaundice and abdominal pain. The patient had had a typical attack of cramps with projection of the pain to the back, followed shortly by syncope and the vomiting of an estimated 1 quart of blood. Later she had melena that lasted 3 days. This was the first time the patient had ever experienced gastro-intestinal bleeding.

A pseudoaneurysm of the left hepatic artery was revealed by abdominal CT - scan with contrast and angiography. At laparotomy the pseudoaneurysm of the left hepatic artery was identified, causing compression and erosion of the main bile duct with hemobilia, inflammated hematoma and perforation. After "Pringle" manoeuvre was applied it becomes possible to stop bleeding and exclude the pseudoanurysm blood flow. A choledochotomy and an exploration of biliary tract were made. There were found coagulums in the billiary tract. The coagulums were removed with lavage. As ligature and suture of the ostium of the pseudoaneurysm proved difficult because of the local inflammatory process, the left hepatic artery was ligated. 
There was made a Roux's anasthomosis between the common bile duct and the small intestine (jejunum). Recovery was uneventful with resolution of jaundice and normalisation of laboratory tests.

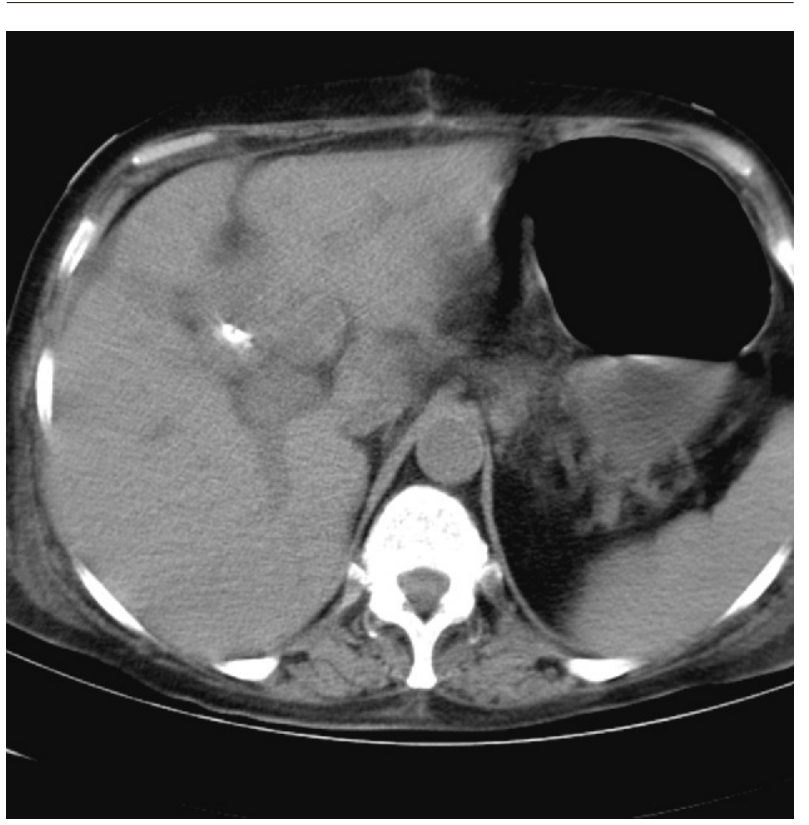

Fig. 1

On the $9^{\text {th }}$ postoperative day an emergent relaparotomy was made by objective considerations and presence of symptoms of biliary peritonitis. An insufficiency of the biliodigestive anastomosis was found. We made a reanastomosis with V?elker drainage. On the 18th day postoperative the patient develops hemorrhagic shock, mastered conservatively. As consequences of heavy disturbances of the homeostasis, with the clinic of polyorganic failure, the patients went in exitus on $23^{\text {th }}$ postoperative day. This is a case of the practice when a routine procedure as laparoscopic cholecystectomy may cause death.

\section{DISCCUSION}

The preoperative aortogram which we performed includes contrast-enhanced CT confirmation of the diagnosis. It seems to have been the first one to be employed in a patient with an hepatic aneurysm. It demonstrated the lesion superbly. The urgency of definitive therapy once the condition has been recognized is best expressed in these disquieting figures. In the 104 previously recorded cases of hepatic-artery aneurysm, about 80 per cent of the patients bled to death. Only about half of these had external evidence of bleeding; that is, hematemesis or melena. The other half bled silently into the peritoneal cavity. Further, of the 22 patients whose aneurysms were recognized during life (21 at operation), only eight survived, and in three of these the diagnosis is in doubt. The surgical correction in these eight was as follows; ligation, four cases $(4,15,16,24)$ (including two in which the diagnosis is in doubt); wiring, one (7); suturing, one (22); suturing of liver, one, (diagnosis in doubt); and endo-aneurysmorrhaphy. In addition, there were approximately a dozen patients who died despite ligation.

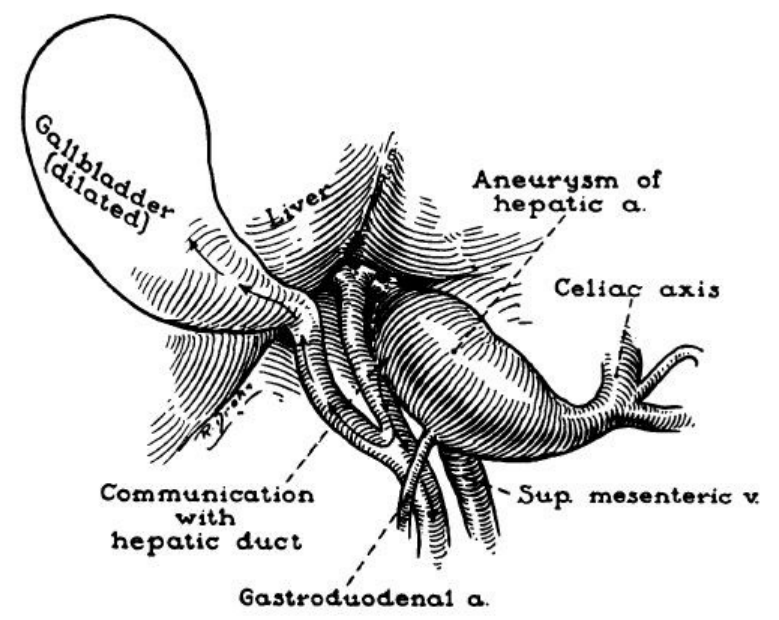

Fig. 2. Anatomic relationships before excision of aneurysm

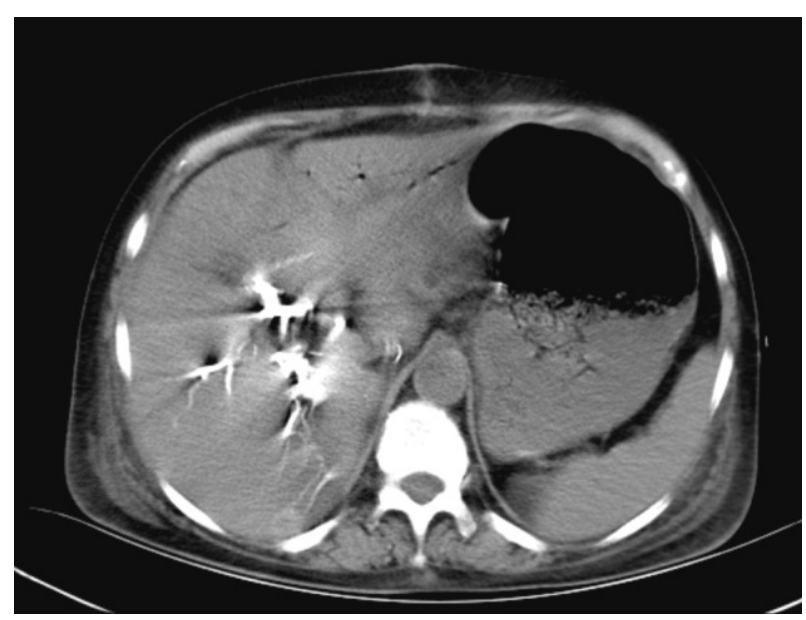

Fig. 3

\section{REFERENCES}

1. Anderson, E. NI.: Aneurisms: Report of Cases.Am. J. Surg., 33: 129, 1919.

2. Barnett, W. O., and J. A. Wagner: Aneuirysm of the Hepatic Artery: A Cause of Obscure Abdominal Hemorrhage. Ann. Surg., 137:561, 1953.

3. Berschadskij, B. I.: Zwei Fiille von Aneurysma der Leberarterie. Chirurgija, 11: 80, 1953;(Abstr.) Zent. f. Chir., 79: 604, 1954.

4. Colmers, F.: Intrahepatisches Aneurysma und Gallenfistel nach Leberzerreissung. Heilung durch Unterbindung der Arteria lhepaticaConiunis. Beitr. klin. Chir., 122: 324, 1921.

5. Daseler, E. H., B. J. Anson, W. C. Hambley and A. F. Reimann: The Cystic Artery and Constituents of the Hepatic Pedicle: A Stuidy of 500 Specimens. Suirg. Gynec. \& Obst., 85:47, 1947.

6. Donaldson, G. A., and E. Hamlin, Jr.: Massive liematemesis Restulting From Rtuptture of a Gas- 
tric-Artery Aneuirysmii: Report of Three Cases. New England J. Med., 243: 369, 1950.

7. Dwight, R. W., and J.W. Ratcliffe: Aneurysm of the Hepatic Artery: Report of a Case Treated by Wiring. Surgery, 31: 915, 1952.

8. Gamarski, J., and M. B. Netto: Aneurisma de Arteria hepatica. Arq. brasil. Med., 43: 257, 1953.

9. Garland, E. A.: Aneurysm of the Celiac Artery. $J$. Internat. Coll. Surgeons, 21: 67, 1954.

10. Giuseffi, J., and C. C. Collins: Successful Cure of a False Aneurysm of the Hepatic Artery. Surgery, 36: 125, 1954.

11. Graham, R. R., and D. Cannell: Accidental Ligation of the Hepatic Artery: Report of One Case, With a Review of the Cases in the Literature. Brit. $J$. Surg., 20: 566, 1933.

12. Haberer, H.: Quoted by Segall, H. N.: An Experimental Anatomical Investigation of the Blood and Bile Channels of the Liver. Surg., Gynec. \& Obst., 37 : 152, 192-3.

13. Hess, H.: Ueber das Aneurysma der Arteria hepatica. Med. Klin., 48: 809, 1953.

14. Johnston, E. V., and B. J. Anson: Variations in the Formation and Vascular Relationships of the Bile Ducts. Surg., Gynec. \& Obst., 94:669, 1952.

15. Kading, K.: Ein Geheitter. Fall von intrahepatischem Aneurysma mit besonderer Beriicksichtigung der traumatischen Leberarterienaneurysmen. Deutsche Ztschr. f. Chir. 150:82, 1919.

16. Kehr, H.: Der erste Fall von erfolgreicher Unterbindung der Art. hepatica propria wegen Aneurysma. Munchen. med. Wchnschr., 50:1861, 1903.

17. Kriickemeyer, K.: tber das Vorkommen seltener Aneurysmen der Aorta und ihrer grossei Aste. Zentralbl. f. allg. Path. u. path. Anat.,90: 363, 1953.

18. Laipply, T. C.: Syphilitic Aneurysm of Celiac Artery. Am. J. M. Sc., 206: 453, 1943.

19. Malloy, H. R., and R. S. Jason: Aneurysm of the Hepatic Artery. Am. J. Surg., 57: 359,1942.
20. McGregor, A. L.: Fatal Hemorrhage From Bile Duct. J. Internat. Coll. Surgeons, 18: 838, 1952.

21. Michels, N. A.: The Hepatic, Cystic, and Retroduodenal Arteries and Their Relations to the Biliary Ducts: With Samples of the Entire Celiacal Blood Supply. Ann. Surg., 133: 503,1951.

22. Paul, M.: A Large Traumatic Aneurysm of the Hepatic Artery. Brit. J. Surg., 39: 278, 1951.

23. Popper, H. L., N. C. Jefferson and H. Necheles: Liver Necrosis Following Complete Interruption of Hepatic Artery and Partial Ligation of Portal Vein. Am. J. Surg., 86: 309, 1953.

24. Quattlebaum, J. K.: Aneurysm of the Hepatic Artery: Report of Three Cases. Ann. Surg., 139: 743, 1954.

25. Rabinovitsch, F. S.: Quoted by R. Alessandri: Aneurysm of the Hepatic Artery. In: Nelson Loose-leaf Surgery. New York, Thomas Nelson \& Sons, 1932, vol. 5, p. 608A.

26. Sampsel, J. W., F. M. Barry and H. D. Steele: Aneurysm of an Anomalous Pancreaticoduodenal Artery: Case Report and Review of the Literature. A. M. A. Arch. Surg., 64: 74, 1952.

27. Schega, H.-W.: Die Ruptur des Aneurysma der Arteria hepatica: Ein Beitrag zur Differentialdiagnose der akuten Mazan-Darmblutung. Chirurg., 23: 125, 1952.

28. Segall, H. N.: An Experimental Anatomical Investigation of the Blood and Bile Channels of the Liver. Surg. Gynec. \& Obst., 37: 152, 1923.

29. Shumay, N. E., and W. T. Peyton: Two Cases of Perforated Intra-abdominal Aneurysm Complicated by Neurological Findings. Surgery, 30: 1012, 1951.

30. Siew, S.: Aneurysm of the Hepatic Artery: Report of a Case and Review of the Literature. South African J. Clin. Sc., 3: 143, 1952.

31. Tandler: Quoted by R. Alessandri: Aneurysm of the Hepatic Artery. In: Nelson Loose-leaf Surgery. New York, Thomas Nelson \& Sons, 1932, vol. 5, p. 608A. 